\title{
Violência simbólica e Cidadania no Futebol: o discurso homofóbico em programas esportivos
}

\section{Luiz Fernando Rodrigues Lemes}

Mestre; Universidade Federal de Goiás, Goiás, GO, Brasil. luizfernando.bvg@gmail.com

\section{Ana Carolina Rocha Pessôa Temer}

Doutora; Universidade Federal de Goiás, Goiás, GO, Brasil. anacarolina.temer@gmail.com

\section{Resumo}

Este artigo pretende compreender como o programa esportivo Jogo Aberto, da TV Bandeirantes, debate sobre comportamentos afetivos envolvendo atletas de equipes de futebol no Brasil. Para isso, foi escolhido o último caso de demonstração afetiva debatido pelo programa (beijo entre Emerson Sheik, ex-jogador do Corinthians, e o chefe de cozinha Isaac Azar). Para isso, partiu-se da concepção de que o futebol é um espaço marcado pela masculinidade e virilidade, que rejeita comportamentos considerados fora desse padrão e, a partir desse cenário, a mídia esportiva deveria assumir a responsabilidade social de debater sobre o tema da sexualidade no esporte a partir da pluralidade de vozes. Foi utilizada a análise de discurso crítica com base nos dispositivos analíticos de Dijk (2015), que permitiu identificar as construções discursivas do programa que contribuíram para a disseminação de preconceitos e estereótipos negativos sobre os homossexuais.

\section{Palavras-chave}

Futebol. Homossexualidade masculina. Programa esportivo.

\section{Introdução}

Com a necessidade de dar aos esportes um viés mais inclusivo e desvincular sua imagem dos aspectos de alta competitividade ${ }^{1}$, a Carta Internacional de Educação Física e Esporte, em 1978, reconheceu a prática esportiva como direito fundamental da segunda

\footnotetext{
${ }^{1} 0$ século XX destinou aos esportes a perspectiva de alto rendimento, formando homens resistentes ao combate e a transformação do corpo em máquinas. Na última metade desse período, a corrida pela perfeição esportiva foi um marco na disputa entre os Estados Unidos e a União Soviética (URSS), juntamente com as disputas armamentistas, espacial e por territórios para a disseminação de suas influências político-ideológicas (capitalismo e socialismo, respectivamente).
} 
geração, ou seja, que determina como dever do Estado fomentar suas práticas para a diminuição das desigualdades sociais (TUBINO, 2005). A partir daquele momento, o esporte passou a ser reconhecido como vetor para a prevenção de doenças e manutenção do equilíbrio corporal e, considerando a saúde como condição fundamental para a existência humana, "[...] o direito à prática esportiva passa a ser, portanto, um direito fundamental." (PAGANELLA, 2007, p. 2).

As práticas esportivas estão expressas na Constituição Brasileira de 1988 (BRASIL, 2016) como atividades que devem ser fomentadas e incentivadas pelo Estado. Por sua vez, o Estatuto da Criança e do Adolescente destina à família, à comunidade e ao Poder Público o dever de "[...] assegurar, com absoluta prioridade, a efetivação dos direitos referentes à vida, à saúde, à alimentação, à educação, ao esporte, ao lazer [...]" (BRASIL, 2014, p. 11). Esse conjunto de legislações destaca a importância das práticas esportivas para a construção da dignidade humana, garantindo às crianças e aos adolescentes o bem-estar e o desenvolvimento de habilidades e da coletividade.

O esporte é relevante no processo de inclusão social, mas também evidencia dilemas estruturais da sociedade brasileira. Portanto, ao mesmo tempo em que serve como espaço para a experimentação da igualdade e a suspensão das desigualdades, também pode promover exclusões de grupos que não compartilham das normas impostas pelos grupos dominantes. Assim, presencia-se nas arquibancadas uma hierarquia baseada na dominação masculina, onde homossexuais sofrem com a imposição de barreiras para o acesso a alguns esportes, como o futebol.

Nesse contexto, os programas esportivos se apresentam como elemento fundamental para a promoção do debate sobre a homofobia no futebol ao propor e agendar o debate sobre o tema, principalmente por se tratar de um assunto controverso nessa modalidade esportiva. Para ilustrar essa discussão, este artigo apresenta um estudo de caso envolvendo o debate sobre a foto do beijo entre o ex-atleta do Sport Club Corinthians Paulista, Emerson Sheik, e o chefe de cozinha Isaac Azar, publicado na rede social Instagram, em 2013, pelo programa Jogo Aberto, da TV Bandeirantes.

Esse caso foi escolhido por se tratar do debate mais recente sobre sexualidade e futebol abordado pela imprensa esportiva envolvendo um dos principais times do Brasil, o Corinthians, que possui a segunda maior do torcida do País, com mais de 27 milhões de torcedores (ÚLTIMA..., 2017). Com isso, este trabalho busca compreender como programas esportivos, diante de um exemplo de troca de afetos entre amigos que ganhou repercussão nacional, abordou a temática da sexualidade no esporte, levando em consideração o contexto sócio-histórico envolvendo a homossexualidade masculina e o futebol. 


\section{Heteronormatividade no futebol}

Os indivíduos são educados para corresponder às expectativas desde a infância, já que “[...] às mulheres estimula-se a ginástica e o ballet, para fins de conformação dos corpos e aos homens incita-se esportes competitivos para fortalecer o corpo e exercitar o convívio regrado entre iguais." (SMIGAY2 apud PEREIRA et al., 2014). Dessa forma, comportamentos e características consideradas femininas serão positivos apenas quando encontrados em mulheres, tornando-se negativos e desqualificantes quando atribuídos aos homens. Os comportamentos que não obedecem à relação binária homem/mulher são considerados desviantes (TORRÃO FILHO, 2005).

Almeida e Soares (2012) destacam que o comportamento homossexual é visto como padrão contrário à conduta heterossexual, considerado algo longe do "normal" no futebol. Diante da heteronormatividade exigida no ambiente futebolístico, essas atitudes são tomadas como comprometedoras para a manutenção do equilíbrio e da sustentação da lógica e da harmonia social, podendo provocar instabilidade na lógica dominante. Para manter a hierarquia de dominação masculina, são usados artifícios para rebaixamento e exclusão dos grupos "indesejados", variando de formas mais sutis (como gritos de guerra, vaias e xingamentos) a atitudes mais violentas (como agressões físicas e assassinatos).

Essas atitudes homofóbicas eliminam identidades plurais dos estádios brasileiros e estabelecem hierarquias que determinam o permitido e o rejeitado, formando grupos hostis ao que é diferente e considerado fora do padrão pelo grupo dominante. "A homofobia é compreendida como um instrumental de dominação, por meio do qual sujeitos e grupos sociais disputam espaços de legitimidade e de reconhecimento e, portanto, de poder." (ALMEIDA; SOARES, 2012, p. 303).

As definições de homofobia apresentadas por alguns autores, como Mott (2003) e Borillo (2010), consideram os aspectos de intolerância, inferiorização, ridicularização e rejeição por meio de atos hostis e atuação arbitrária em relação às pessoas que possuem comportamentos afeminados (não sendo necessário que as ofensas se direcionem apenas aos homossexuais, mas também àqueles que possuem características que não se coadunam com o comportamento heteronormativo). Esse tipo de perseguição pode se materializar por meio de gritos vulgares até o uso de meios brutais, como agressões e assassinatos.

A exigência em tornar explícita a masculinidade exige monitoramento constante das próprias ações na necessidade de o homem expressar a sua virilidade a um grupo que

\footnotetext{
SMIGAY, Karin Ellen von. Relações violentas no espaço da intimidade. Drama privado ou tragédia pública? Tese de doutorado (doutorado em Psicologia Social) - Pontifícia Universidade Católica de São Paulo, São Paulo, 2000.
} 
validará ou rejeitará essa condição (BOURDIEU, 2012). No futebol, essa situação fica evidente em rituais dos personagens envolvidos no drama futebolístico, como em divididas de bolas, comemorações que representam a eliminação do oponente, cantos entoados contra a torcida adversária e a arbitragem, etc. Os comportamentos que não se enquadram nesse perfil são criticados e estigmatizados.

[...] a virilidade tem que ser validada pelos outros homens, em sua verdade de violência real ou potencial, e atestada pelo reconhecimento de fazer parte de um grupo de "verdadeiros homens". Inúmeros ritos de instituição, sobretudo os escolares ou militares, comportam verdadeiras provas de virilidade, orientadas no sentido de reforçar solidariedades viris. (BOURDIEU, 2012, p. 65).

Welzer-Lang (2001) aponta que a visão naturalista que define a superioridade masculina e determina a forma como os homens devem se comportar indicam uma normatização que define o "homem natural" como aquele que não possui perfil efeminado. Por outro lado, os homens que se distinguem por meio da aparência (não sendo necessariamente homossexuais) ou pela atração por pessoas do mesmo sexo são deslocados para o grupo dos "dominados", compreendendo qualquer indivíduo que não se enquadre na lógica heteronormativa masculina.

Essa construção da superioridade natural masculina e da naturalidade dos relacionamentos heterossexuais, de acordo com Bourdieu (2012), demonstra que a soberania da heterossexualidade masculina é construída socialmente como padrão universal. Algumas instituições garantem a perpetuação dessa ordem: a Família (primeiro lugar em que se tem a visão da divisão binária entre homem/mulher e da hierarquia baseada na figura do patriarca), a Igreja (que durante séculos apresenta a moral familiarista baseada em valores patriarcais) e a Escola (que mesmo após liberta das ligações com a Igreja, mantém a reprodução de uma hierarquia patriarcal sustentada por ideias de teólogos, médicos e moralistas).

\section{Violência simbólica no futebol}

Além das violências físicas frequentemente divulgadas nos estádios (agressões, tumultos entre torcidas organizadas e, inclusive, assassinatos), a violência simbólica ${ }^{3}$ também é predominante nesses espaços, principalmente por meio de cantos. Para

\footnotetext{
3 Para Bourdieu (1997, p. 22), "A violência simbólica consiste em uma violência que se exerce com a cumplicidade tácita dos que a sofrem e também, com frequência, dos que a exercem, na medida em que uns e outros são inconscientes de exercê-la ou de sofrê-la.". Dessa forma, não se usa a coação física, mas a imposição de um modo de pensamento por meio do domínio econômico, social, cultural e intelectual.
} 
compreender a concepção desse termo, deve-se falar antes sobre os conceitos de "habitus" e campo. Em relação ao primeiro, refere-se a um esquema de percepção, reflexão e visão evidenciados no corpo e na mente que possibilitam a classificação de si próprio e dos demais indivíduos por meio de gestos e formas de ver o mundo (SALVINI; SOUZA; MARCHI JUNIOR, 2012).

O habitus, que é o princípio gerador de respostas mais ou menos adaptadas às exigências de um campo, é produto de toda a história individual, bem como, através das experiências formadoras da primeira infância, de toda história coletiva da família e da classe; em particular, das experiências em que se exprime o declínio da trajetória de toda uma linhagem e que podem tomar a forma visível e brutal de uma falência ou, ao contrário, manifestarse apenas como regressões insensíveis. (BOURDIEU, 2004, p. 131).

Por sua vez, o campo possibilita a atuação em um espaço de lutas e concorrência entre os detentores de poder (dominantes) e os dominados, onde os primeiros estabelecem estratégias para a manutenção das posições de superioridade e o acesso aos instrumentos de interesse, garantindo prestígio ao grupo. (SALVINI; SOUZA; MARCHI JUNIOR, 2012).

\footnotetext{
Um campo é um espaço social estruturado, um campo de forças - há dominantes e dominados, há relações constantes, permanentes de desigualdade, que se exercem no interior desse espaço - que é também um campo de lutas para transformar ou conservar esse campo de forças. Cada um, no interior desse universo, empenha em sua concorrência com os outros a força (relativa) que detém e que define sua posição no campo e, em consequência, suas estratégias. (BOURDIEU, 1997, p. 57).
}

No campo do futebol, os agentes estabelecem condições para a manutenção do prestígio e da superioridade de um grupo em detrimento de outro. Por sua vez, o "habitus" atua no processo de interiorização dos valores e identidades construídas durante o processo de formação do agente por meio da história individual e das experiências coletivas. Esse processo permite ao indivíduo internalizar percepções e ações de uma estrutura externa, garantindo a reprodução das ações interiorizadas, como a forma de pensar e se comportar no ambiente esportivo. Nesse espaço, cada agente busca mais distinção social por meio do poder simbólico, sendo distribuídas posições conforme o capital social, cultural e econômico de cada indivíduo pertencente ao campo.

Nessa relação, o dominante usa instrumentos que garantem a manutenção da ordem vigente e a exclusão do "novo", exercendo o seu poder sobre os demais grupos. Porém, essa situação não se configura apenas pelo uso da força ou de ações diretas exercidas pelos dominantes sobre os dominados. A dominação pode ocorrer de maneira camuflada, de modo 
que aqueles que são submetidos a certas imposições não as percebem, configurando a violência simbólica.

Esse cenário é evidenciado por meio de manifestações nas arquibancadas que indicam a permissividade ou a rejeição de grupos, consolidadas por meio de estruturas verbais que determinam as representações coletivas. Toledo $(1993$, p. 21) destaca quatro modalidades de expressões observadas nas arenas brasileiras: “[...] vaias, xingamentos, cantos e/ou gritos de guerra.”. Em relação aos cânticos, foco deste trabalho, o autor subdivide em outras quatro categorias: os de incentivo à equipe, os de autoafirmação, os de protestos e os intimidadores. As expressões ofensivas e discriminatórias contra adversários estão presentes nos quatro tipos de cantos, a maioria expressando a temática da sexualidade. Em relação aos dois primeiros, há uma valorização das características de virilidade, demonstrando força em comparação aos adversários. Já em relação ao protesto e intimidação, as expressões indicam o oposto, geralmente inferiorizando o opositor por meio de sentenças que indicam a passividade sexual.

O espaço do futebol, principalmente o das torcidas organizadas, funciona como a "casa dos homens" - um ambiente de homens e para homens que constrói a masculinidade para os que estão "entrando" e, ao mesmo tempo, reforça a masculinidade entre os membros "veteranos". Esse espaço viril exclui todos aqueles que se insurgem contra a "virilidade triunfante" e a feminilidade em geral, configurando-se como um codificador de condutas masculinas. (COELHO, 2009, p. 87).

Dessa forma, a arena esportiva contrasta com os preceitos dos direitos humanos, considerados como universais e que decorrem do reconhecimento da dignidade de todo ser humano (SOARES, 2013). Neste sentido, são considerados fundamentais e naturais originários do direito à vida sem qualquer tipo de discriminação, intolerância ou preconceito.

\section{Subcidadania e acesso à comunicação}

Cortina (2005) define a cidadania como um conceito mediador, por se referir diretamente ao sentimento de pertença a uma sociedade, mas também por ser um termo que exige a racionalidade de justiça.

A cidadania é primordialmente uma relação política entre um indivíduo e uma comunidade política, em virtude da qual o indivíduo é membro de pleno direito dessa comunidade e a ela deve lealdade permanente. 0 estatuto de cidadão é, em consequência, o reconhecimento oficial da 
integração do indivíduo na comunidade política, comunidade que, desde as origens da era moderna, adquire a forma de Estado nacional de direito. (CORTINA, 2005, p. 31).

Avançando ainda mais na definição, Cortina (2005) estrutura a história da cidadania entre a "aproximação dos semelhantes" e a "separação em relação aos diferentes". Dessa forma, a organização da sociedade passa pela identificação das características semelhantes que aproximam membros em um determinado grupo, mas também busca evidenciar as diferenças em relação aos que são considerados de "fora". Portanto, o conceito de cidadania nasce na dialética entre o "interno" e o "externo", que prega a união entre aqueles que são semelhantes e a rejeição/separação aos diferentes.

A rejeição do grupo LGBT no cenário esportivo situa seus membros em um status de subcidadania ${ }^{4}$, termo inicialmente apresentado por Souza (2003) a partir da noção de "habitus" de Bourdieu, da qual se consolida uma visão de mundo e hierarquia de maneira imperceptível, estruturada por meio de "acordos e consensos sociais mudos e subliminares" que articulam atos preconceituosos profundos, naturalizados e invisíveis. A partir desse conceito, Souza (2003) aponta a construção dos “habitus" primário, secundário e precário, que se interpenetram em diversas situações, mas que devem ser analisados separadamente.

Em relação ao "habitus primário", "[..] o que está em jogo é a efetiva disseminação da noção da dignidade do agente racional que o torna agente produtivo e cidadão pleno." (SOUZA, 2003, p. 176). Nessa concepção, estabelece-se um padrão mínimo de participação na esfera social, o que permite ao sujeito o compartilhamento da noção de cidadania. A partir dessa definição, torna-se possível compreender os demais "habitus":

\begin{abstract}
O "habitus precário" seria o limite do "habitus primário" para baixo, ou seja, seria aquele tipo de personalidade e de disposições de comportamento que não atendem às demandas objetivas para que, seja um indivíduo, seja um grupo social, possa ser considerado produtivo e útil em uma sociedade de tipo moderno e competitivo [...] 0 que estamos chamando de "habitus secundário" tem a ver com o limite do "habitus primário" para cima, ou seja, tem a ver com uma fonte de reconhecimento e respeito social que pressupõe, no sentido forte do termo, a generalização do "habitus primário" para amplas camadas da população de uma dada sociedade. (SOUZA, 2003, p. 167).
\end{abstract}

A partir desses conceitos, Souza (2003) aponta que em sociedades periféricas, como a brasileira, o "habitus precário" é um fenômeno de massa estruturado a partir de armações

\footnotetext{
O subcidadão é aquele que não tem acesso aos direitos e não participa direta e ativamente dos processos de decisão de uma comunidade (CIRINO; TUZZO, 2016). No caso dos homossexuais no futebol, a subcidadania refere-se ao impedimento de acesso ao estádio pela imposição de barreiras simbólicas e pela submissão às ordens, comportamentos e normas impostas pelos cidadãos que, neste caso, baseia-se na masculinidade viril.
} 
invisíveis que desqualificam sujeitos e grupos sociais precarizados como subcidadãos. Diante desse cenário, os meios de comunicação surgem como um importante caminho para o exercício da cidadania com a possibilidade de dar voz para que os homossexuais reivindiquem direitos. Porém, também podem ser usados para a disseminação de estereótipos negativos que possibilitem práticas homofóbicas. Leal e Carvalho (2009) destacam que os meios de comunicação são importantes espaços para o debate sobre casos de homofobia e a cobertura política e cultural LGBT (lésbicas, gays, bissexuais, travestis, transexuais e trangêneros). Contudo, os autores apontam que a falta de confiança desse grupo em relação aos meios de comunicação pode ser resultado dos silêncios e omissões sobre os casos de homofobia e a discordância sobre a forma que as notícias à respeito da homossexualidade são construídas. Portanto, pode-se considerar que o silenciamento das discussões relacionadas a essas minorias no futebol é resultado do agendamento de notícias esportivas que desconsideram temas de interesse sobre a homossexualidade.

O jornalismo pode desvirtuar seu papel social ao ser omisso e negligenciar a sua função de dar voz à diversidade de grupos e indivíduos. "Quando a imprensa se recusa à pluralidade de fontes, acaba por desrespeitar os direitos humanos, infringindo mais especificamente o princípio ético de sempre ouvir o outro lado de um assunto polêmico." (MEDEIROS, 2016, p. 223). Portanto, o jornalismo, inclusive o esportivo, pode realizar coberturas tendenciosas, ouvindo sempre as mesmas fontes e silenciando pontos de vistas.

Para Dijk (2015), uma importante forma de reprodução e propagação discursiva do poder ocorre com o acesso ao discurso e eventos comunicativos. Dessa forma, a acessibilidade aos meios de comunicação não é igualitária, pois se baseia em uma distribuição que concede aos grupos dominantes o acesso e o exercício da influência sobre o público. Portanto, o poder baseia-se no privilégio de um determinado grupo acessar as riquezas, o discurso e o status na sociedade e, para isso, muitos grupos utilizam-se da dominância como

[...] uma forma de abuso de poder social, isto é, como o exercício moral e legalmente ilegítimo de controle sobre outros em benefício ou interesse próprio de alguns, frequentemente resultando em desigualdade social. [...] 0 poder social e a dominância são frequentemente organizados e institucionalizados, de forma a permitir um controle mais efetivo e possibilitar formas rotineiras de reprodução do poder. (DIJK, 2015, p. 88).

A naturalização dos comportamentos baseados na heterossexualidade é construída, reforçada e compartilhada por instituições legitimadas na sociedade (Igreja, Escola, Mídia, etc.). Deve-se compreender que as relações entre essas entidades são baseadas em 
complexas práticas sociais envolvendo um jogo de poder que determina quem terá acesso aos meios de comunicação (DARDE, 2008). Mais do que isso, os profissionais de comunicação, mesmo inconscientemente, podem contribuir para a disseminação de estereótipos negativos relacionados aos homossexuais, reproduzindo expressões e brincadeiras que são típicas das arquibancadas.

\section{0 caso e o programa Jogo Aberto}

Em 2013, o ex-jogador do Corinthians, Emerson Sheik, publicou em sua rede social Instagram a foto do beijo com o chefe de cozinha Isaac Azar com o objetivo de criticar a homofobia no futebol. Porém, a atitude foi mal recebida por boa parte dos internautas, seguidores e torcedores da equipe paulista, que reagiram com mensagens homofóbicas. Diante de tal cenário, o programa Jogo Aberto inseriu a publicação de Emerson Sheik como pauta para o debate na programação já no dia seguinte ao post.

A atração da Rede Bandeirantes de Televisão, que completou 12 anos de transmissão em fevereiro de 2019, é transmitida de segunda a sexta-feira, das 11 horas às 13 horas. A apresentação do programa é da ex-miss Brasil Renata Fan e conta com os comentários de Denílson Araújo, Ronaldo Giovanelli (ambos ex-jogadores de futebol), Ulisses Costa, Paulo Morsa e, eventualmente, outros convidados. Em 2009, uma audiência pública promovida pela Comissão de Direitos Humanos e Minorias da Câmara dos Deputados apontou o Jogo Aberto como campeão de reclamações no Ranking de Baixaria na TV após levantar 88 denúncias sobre desrespeito às torcidas, incitação à violência e vocabulário impróprio para o horário (CAMPANHA..., 2009).

Dada a importância do objeto, o recorte considerou o último caso de troca de afetos entre atletas masculinos debatidos pelos interlocutores do programa. Outro fator que motivou a seleção deu-se pela repercussão nacional do fato, já que se tratava de um jogador do Corinthians, time com a segunda maior torcida do Brasil. Também se ressalta a reação homofóbica de parte dos torcedores dessa agremiação esportiva após a publicação da foto, já que alguns integrantes vestidos com camisas e adereços da organizada Fiel Torcida Jovem Camisa 12 levaram faixas escritas "Vai beijar a PQP... aqui é lugar de homem" e "viado não". 0 material foi obtido após breve busca por notícias, debates, entrevistas e reportagens que apresentassem a discussão sobre a homossexualidade ou trocas de afetos entre homens no futebol brasileiro a partir de mecanismos de buscas disponíveis na internet. Para isso, foram utilizadas as palavras-chave "homossexualidade", "futebol", "gay", usadas em diferentes formas de combinações. 
Após a seleção da reportagem mais recente veiculada em uma emissora de televisão identificada pelo site de busca, o material foi transcrito levando em consideração os aspectos verbais e não-verbais do debate. Além disso, também foi considerada a trajetória profissional e pessoal dos personagens que debateram o caso envolvendo o ex-atleta do Corinthians e os atores que foram objetos de discussão pelo programa.

Terminada essa etapa, foram utilizados os dispositivos analíticos de Dijk (2015) que possibilitaram identificar a construção das estruturas dos discursos do programa esportivo. Para isso, foram considerados elementos que indicavam uma relação discriminatória contra as minorias por meio de estruturas não verbais e verbais. 0 discurso homofóbico costuma enfatizar aspectos positivos dos grupos de poder (elites) e ressaltar aspectos negativos das minorias (homossexuais masculinos). Assim, o “[...] quadrado 'ideológico' aplica-se não apenas à dominação [...], mas também, em geral, à polarização intragrupal-extragrupal em práticas sociais, discursos e pensamentos." (DIJK, 2015, p. 137), sendo que o preconceito é formulado a partir da posição ocupada pelo sujeito.

A enorme variedade de discursos racistas [neste caso, homofóbicos] não apenas reflete as várias representações sociais subjacentes, mas também, em especial, adapta-se a diferentes contextos de produção: quem disse o que, onde, quando e com que objetivos. A teoria do contexto também explica em parte por que, apesar do consenso [...] dominante, nem todas as falas acerca das minorias serão as mesmas. (DIJK, 2015, p. 140).

Neste trabalho foi realizada a transcrição dos debates e a descrição não verbal dos interlocutores. Também se ressalta a identificação de movimentos semânticos que destacam aspectos positivos do grupo de poder em detrimento de elementos negativos das minorias, como os exemplos apresentados no Quadro 1 (os exemplos utilizados na tabela não necessariamente foram ditos durante a apresentação do programa):

Quadro 1 - Exemplos de movimentos semânticos

\begin{tabular}{|c|l|}
\hline Movimentos Semânticos & \multicolumn{1}{c|}{ Exemplos } \\
\hline Negação aparente & Nós não temos nada contra, mas... \\
\hline Concessão aparente & Alguns deles são inteligentes, mas em geral... \\
\hline Empatia aparente & $\begin{array}{l}\text { É claro que os homossexuais enfrentam problemas, } \\
\text { mas... }\end{array}$ \\
\hline Ignorância aparente & Eu não sei, mas... \\
\hline Desculpa aparente & Desculpe-me, mas... \\
\hline Inversão (culpar a vítima) & Não eles, mas nós é que somos as vítimas... \\
\hline Transferências & Eu não me importo, mas as torcidas... \\
\hline
\end{tabular}

Fonte: adaptado de DIJK (2015). 
No quadro se destacam alguns dispositivos analíticos com a denominação "aparente". Isso significa que em construções discursivas de sujeitos pertencentes a grupos dominantes se evidenciam aspectos positivos de grupos minoritários como uma técnica de autoapresentação positiva, ou seja, a tentativa do indivíduo em apresentar uma impressão não homofóbica. Porém, o restante da frase passa a ter um sentido negativo, contradizendo a primeira parte.

\section{Discurso homofóbico no programa Jogo Aberto}

Para comentar este caso, o Jogo Aberto propôs uma enquete para que a audiência do programa avaliasse a validade dos protestos dos torcedores contra o beijo de Emerson Sheik. Na ocasião, Denilson e Giovanelli discutiram sobre o episódio de maneira exaltada. 0 primeiro, que durante a carreira profissional defendeu São Paulo e Palmeiras, começa a destacar que um dos principais problemas dos corintianos é o fato de não saberem brincar. Giovanelli, que se destacou atuando como goleiro do Corinthians, tenta se defender das acusações do colega de profissão. No programa Jogo Aberto do dia 20 de agosto de 2013, Ronaldo Giovanelli e Denílson tiveram a seguinte conversa:

\footnotetext{
Giovanelli: Quando eu tomava gol nem dormia direito.

Denílson: Vocês gostam de zoar os outros e não gostam de serem zoados.

Giovanelli: Não, não. Vou explicar.

Denílson: É sim! Esse é o problema de vocês [...].

Giovanelli: Posso falar ou não?

Denílson: Não pode, não. Porque vocês não gostam de ser zoados [sic]. Vocês gostam de zoar e não gostam de ser zoados [sic]. Chupa essa manga, irmão. Chupa essa manguinha. 0 cara beijou na boca e é corintiano. E vai Corinthians e gavião virou beija-flor. A realidade é essa [...]. (Grifo nosso)
}

Neste trecho, percebe-se que os interlocutores veem o ato de afetividade entre Emerson Sheik e Isaac Azar como algo inaceitável para os padrões do futebol. Dessa forma, a atitude do ex-atleta do Corinthians serve como pretexto para "brincadeiras" de torcedores rivais, devendo ser aceito pelos corintianos. 0 trecho também destaca a reprodução de termos pejorativos como a transformação do gavião (mascote da equipe paulista famosa por ser uma ave predadora) em beija-flor (animal colorido que se alimenta de néctar e se destaca pela graciosidade). A discussão é interrompida pela apresentadora Renata Fan que relembra outro termo pejorativo, o bambi, que é costumeiramente usado para se referir preconceituosamente aos torcedores do São Paulo. Ainda no Programa Jogo Aberto de 20 de agosto de 2013, Renata Fan e Denílson conversaram: 
Renata Fan: Quer dizer que eles criaram o bambi e você quer criar o beija-flor agora?

Denílson: 0 gavião virou beija-flor mesmo, véio [sic]. Virou beija-flor o gavião. Sem essa, véio [sic]. Zoam pra caramba, são zoados ficam bravinhos. Aguenta, irmão! Aguenta! Não tem essa. (Grifo nosso).

Nos dois trechos destacados, percebe-se que todas as condutas que não condizem com o padrão imposto pela masculinidade no futebol são rejeitadas e estigmatizadas. Durante a exibição do programa, os interlocutores concordam com a ação de parte dos torcedores que protestaram contra a atitude de Emerson Sheik no centro de treinamentos do Corinthians. Principalmente quando o comentarista corintiano Osmar de Oliveira afirma que a torcida alvinegra agiu rápido para inibir comportamentos homoafetivos, característica que seria distinta a das demais torcidas, como demonstra esta última parte da conversa entre os interlocutores do Jogo Aberto.

\author{
Osmar de Oliveira: A única diferença é que o gavião foi reclamar rápido. \\ Denílson: 0 gavião não! 0 beija-flor! \\ Osmar de Oliveira: Reclamou e falou "isso não é aqui". \\ Denílson: Foi. Quatro foram lá reclamar. (Grifo nosso).
}

Nesse trecho, além de Osmar de Oliveira destacar que parte da torcida corintiana protestou contra a atitude de Sheik, Denílson utiliza a técnica da ironia para ridicularizar a baixa adesão dos torcedores na manifestação. Durante todo o debate ocorre o processo de “inversão de culpa”. Nessa estruturação do discurso, as vítimas deixam de ser Emerson Sheik e Isaac Azar (mesmo sendo heterossexuais, são vítimas de ataques LGBTfóbicos por parte dos torcedores) e passa a ser a torcida corintiana por ter a imagem de masculinidade típica do ambiente futebolístico afetada pelo gesto de afetividade envolvendo um atleta da equipe com outro homem.

\title{
7 Considerações Finais
}

A construção discursiva dos debates destaca sentidos negativos em relação aos homossexuais masculinos, consolidados principalmente em preconceitos baseados em estereótipos ofensivos ditos por ex-atletas de futebol e que, atualmente, pertencem a programas esportivos. Dessa forma, os interlocutores do programa contribuem para a consolidação e disseminação de atitudes preconceituosas que são replicadas em locais de prática esportiva, como o protesto contra o beijo de Emerson Sheik. Também se evidencia que os sujeitos participantes do programa pertencem a um grupo de poder no futebol que buscam uma autoapresentação positiva e uma representação negativa do outro. 
A análise do debate do programa Jogo Aberto envolvendo o beijo entre um atleta de futebol e um amigo do mesmo sexo aponta que a mídia esportiva também é responsável pela construção e disseminação de estereótipos negativos e preconceitos em relação aos homossexuais masculinos. Por meio da ridicularização da publicação da foto em uma rede social, evidencia-se que o grupo de poder no futebol é composto por homens que adotam posturas viris e de rejeição em relação aos comportamentos que não coadunam com o padrão aceitável na modalidade esportiva. Ainda que os personagens envolvidos na matéria debatida pelos comentaristas do Jogo Aberto não se declarem como homossexuais, a posição e o discurso dos interlocutores permitem a disseminação da ideia de que o futebol não é um espaço para homossexuais, contribuindo para a manutenção do poder da masculinidade nas arquibancadas.

A transferência de responsabilidade, a inversão (culpar a vítima) e a negação aparente foram estratégias eficazes para a transmissão de uma imagem positiva dos interlocutores e, ao mesmo tempo, desviar as evidências de práticas homofóbicas nos discursos. Tal situação contribui para a rejeição dos homossexuais, reforçando ainda mais o status de subcidadania desse grupo ao se criar uma barreira imperceptível que os impede de acessar os estádios sem se submeter às normas do grupo de poder.

Outro ponto negligente do programa foi não proporcionar a pluralidade de vozes no debate, pois os envolvidos no beijo (Sheik e Azar) e pessoas/grupos que defendem a diversidade no esporte não foram convidados para discutir o caso. Em contrapartida, indivíduos conhecidos pela postura heteronormativa e pela disseminação de termos pejorativos (como o "bambi") participaram do debate e destacaram estereótipos negativos dos homossexuais, reforçando as características e condutas aceitas no âmbito futebolístico e contribuindo ainda mais para estigmatizar a imagem do grupo minoritário.

Os efeitos desse tipo de debate possibilitam que opiniões distintas à heteronormatividade sejam silenciadas e resultam na manutenção de discursos homofóbicos entre os atores envolvidos no esporte, como os torcedores. Além disso, o programa ainda aponta indícios de que parte dos jornalistas esportivos ainda não está preparada para discutir a questão da homossexualidade masculina no futebol. Orientados a seguir um padrão editorial que privilegia uma cobertura setorizada diária, o debate sobre assuntos que não interferem diretamente nos resultados dentro de campo acaba sendo tratado de maneira superficial, sem a devida preocupação com técnicas que são essenciais para a pluralidade de opiniões, resultando na consolidação de apenas um ponto de vista.

0 tipo de debate proporcionado pelo Jogo Aberto, baseado em brincadeiras envolvendo o reforço da masculinidade e virilidade, contribui para que as manifestações 
preconceituosas nos estádios sejam ainda mais reforçadas e naturalizadas. Enquanto isso, o homossexual se aprofunda em uma condição de subcidadania e sem perspectivas de mudanças significativas sobre tal situação em curto prazo no futebol, restando duas situações: assujeitar-se ao padrão normativo das arquibancadas para continuar com o direito de frequentar os estádios ou se afastar dos eventos que envolvem a modalidade esportiva.

\section{Referências}

ALMEIDA, Marco Bettine; SOARES, Alessandro da Silva. 0 futebol no banco dos réus: caso da homofobia. Movimento, Porto Alegre, v. 18, n. 1, p. 301-321, jan/mar. 2012.

BORILLO, Daniel. Homofobia: história e crítica de um preconceito. Belo Horizonte: Autêntica Editora, 2010.

BOURDIEU, Pierre . Sobre a televisão. Rio de Janeiro: Jorge Zahar, 1997.

BOURDIEU, Pierre. Coisas Ditas. São Paulo: Brasiliense, 2004.

BOURDIEU, Pierre. A Dominação Masculina. 11. ed. Rio de Janeiro: Bertrand Brasil, 2012.

BRASIL. [Constituição (1988)]. Constituição da República Federativa do Brasil de 1988. Brasília, DF: Presidência da República, [2016]. Disponível em: https://www.planalto.gov.br/ccivil_03/constituicao/constituicao.htm. Acesso em: 22 jun. 2019.

BRASIL. Estatuto da Criança e do Adolescente. Lei $\mathrm{n}^{\circ}$ 8.069, de 13 de julho de 1990, e legislação correlata. 12. ed. Brasília: Câmara dos Deputados, Edições Câmara, 2014.

CAMPANHA divulga 16 Ranking da Baixaria na TV. Câmara dos Deputados. Comissão de Direitos Humanos e Cidadania, Brasília, 26 ago. 2009. Disponível em: http://www2.camara.leg.br/atividade-legislativa/comissoes/comissoes-

permanentes/cdhm/noticias/campanha-divulga-16o-ranking-da-baixaria-na-tv. Acesso em: 13 nov. 2018

COELHO, Juliana Affonso Gomes. Voleibol: um espaço híbrido de sociabilidade esportiva. In: TOLEDO, Luiz Henrique de; COSTA, Carlos Eduardo (org.). Visão de Jogo: antropologia das práticas esportivas. 1 ed. São Paulo: Editora Terceiro Nome, 2009.

CIRINO, José Antônio Ferreira; TUZZO, Simone Antoniaci. Cidadania midiática: a pirâmide da desigualdade, do sub ao supracidadão. In: CIRINO, José Antônio Ferreira; BRAGA, Claudomilson (org.). Mídias e Desigualdades. Goiânia: Kelps, 2016.

CORTINA, Adela. Cidadãos do Mundo: para uma teoria da cidadania. São Paulo: Edições Loyola, 2005.

DARDE, Vicente William da Silva. A construção de sentidos sobre a homossexualidade na mídia brasileira. Em Questão, Porto Alegre, v. 14, n. 2, p. 223-234, jul./dez. 2008. 
DIJK, Teun A. van. Discurso e Poder. 2. ed. São Paulo: Contexto, 2015.

LEAL, Bruno Souza; CARVALHO, Carlos Alberto de. Sobre jornalismo e homofobia ou: pensa que é fácil falar. Revista da Associação Nacional dos Programas de Pós-Graduação em Comunicação - E-Compós, Brasília, v. 12, n. 2, p. 1-15, maio/ago. 2009.

MEDEIROS, Magno. Cidadania, Direitos Humanos e Jornalismo: percalços históricos e violência institucionalizada. In: MORAES, Ângela; SIGNATES, Luiz (org.). Cidadania Comunicacional: teoria, epistemologia e pesquisa. Goiânia: Gráfica UFG, 2016.

MOTT, Luiz R. B. Homossexualidade: mitos e verdades. Salvador: Grupo Gay da Bahia, 2003.

PAGANELLA, Marco Aurélio. O esporte como direito fundamental e como instrumento de políticas públicas, sociais e educacionais à luz do Direito brasileiro. Revista de Direito Constitucional e Internacional - RDCI, São Paulo, v. 17, n. 69, p. 206-238, out./dez. 2007.

PEREIRA, Annelyse Santos Lira Soares et al. Preconceito contra homossexuais no contexto do futebol. Psicologia \& Sociedade, Florianópolis, v. 26, n. 3, p. 737-745, 2014.

SALVINI, Leila; SOUZA, Juliano de; MARCHI JUNIOR, Wanderley. A violência simbólica e a dominação masculina no campo esportivo: algumas notas e digressões teóricas. Revista Brasileira de. Educação. Física e. Esporte, São Paulo, v. 26, n. 3, p. 401-10, jul./set. 2012.

SOARES, Maria Victória de Mesquita Benevides. Cidadania e Direitos Humanos. São Paulo: Instituto de Estudos Avançados da Universidade de São Paulo, 2013. Disponível em: http://www.egov.ufsc.br/portal/sites/default/files/anexos/16070-16071-1-PB.pdf. Acesso em: 14 nov. 2017.

SOUZA, Jessé. A construção social da subcidadania: para uma sociologia política da modernidade periférica. Belo Horizonte: Editora UFMG; Rio de Janeiro: IUPERJ, 2003.

TOLEDO, Luiz Henrique de. Por Que Xingam os Torcedores de Futebol? Cadernos de Campo, São Paulo, v. 3, n. 3, p. 20-29, 1993.

TORRÃO FILHO, Amílcar. Uma questão de gênero: onde o masculino e o feminino se cruzam. Cadernos Pagu, Campinas, v. 24, p. 127-152, 2005.

TUBINO, Manoel. O Direito à Educação Física e ao Esporte. Corpus et Scientia, Rio de Janeiro, v. 1, n. 1, 2005.

ÚLTIMA pesquisa LANCE/Ibope mostrou Flamengo na frente, mas vantagem menor para o Timão. Lance! Futebol Nacional, Rio de Janeiro, 10 maio 2017. Disponível em: http://www.lance.com.br/futebol-nacional/flamengo-segue-com-maior-torcida-masvantagem-para-timao-cai.html. Acesso em: 3 jan. 2017.

WELZER-LANG, Daniel. A construção do masculino: dominação das mulheres e homofobia. Revista Estudos Feministas, Florianópolis, v. 9, n. 2, 2001. 


\title{
Symbolic violence and Citizenship in Football: the homophobic discourse in sports programs
}

\begin{abstract}
This article intends to understand how the sports program Jogo Aberto, TV Bandeirantes, debates about affective behaviors involving athletes of soccer teams in Brazil. For that, the last case of affective demonstration debated by the program was chosen (a kiss between Emerson Sheik, former player of Corinthians, and Isaac Azar). It was based on the conception that soccer is a space marked by masculinity and virility that rejects behaviors considered outside of this pattern and, in this case, the sports media should assume the social responsibility to discuss the theme of sexuality in sport from the plurality of voices. Critical discourse analysis was used based on the analytical devices of Dijk (2015), which allowed identifying the discursive constructions of the program that contributed to the spread of prejudices and negative stereotypes about homosexuals.
\end{abstract}

\section{Keywords}

Football. Male homosexuality. Sports program.

Recebido em 10/05/2018

Aceito em11/05/2019 